\title{
It's just a matter of time: The perceptions of growing our own students of the Growing Our Own program
}

\begin{tabular}{|c|c|}
\hline $\begin{array}{c}\text { Nicoli Barnes } \\
\text { Charles Darwin University } \\
\text { nicoli.barnes@utas.edu.au }\end{array}$ & $\begin{array}{c}\text { Ben van Gelderen } \\
\text { Charles Darwin University } \\
\text { bvangelderen@nungalinya.edu.au }\end{array}$ \\
\hline \multicolumn{2}{c|}{ Kelly Rampmeyer } \\
Charles Darwin University
\end{tabular}

Key words: Indigenous education; initial teacher education; remote education

\section{Introduction}

In this paper, we give the Growing Our Own students ${ }^{1}$ the opportunity to tell us their perceptions of the Growing Our Own program. As Growing Our Own partners and lecturers, it has been easy to provide our view of what we see happening when we work in the Growing Our Own program. We are aware that what this program offers to us, both personally and professionally, is highly valuable. We commonly express the privilege we feel to be working in the program and our talk often turns to the care that is given to and received from the people involved: our students, our mentor teachers, our schools, our relationship with Catholic Education, our teaching, our learning (and learning and learning), our joys, our failures, the extreme hilarity and the sadness we feel at some of the stories we hear of the struggles our students encounter.

Contained within all these discussions is our unquestioning assumption that Growing Our Own works. We see it and experience it every time we enter the communities that we work with and despite all the things that could go wrong-intercultural misunderstandings, the danger of the elements and isolation, internal community issues, a lack of language (on our behalf), an often inflexible, mainstream institutional system at schooling and university levels, logistical issues with travel, resources, the extreme need for flexibility—it still works.

Evaluations have been done in the past and will be again, so we know that it works (Ebbeck, 2009; Giles, 2010; Maher, 2010). We, as lecturers, regularly share all this, strongly believing that Growing Our Own works from our perspective. But are we wrongly assuming that it is the same for our students? In this paper, we explore what our Growing Our Own students believe is happening that helps them (or doesn't) to engage, learn, grow and succeed as fully trained teachers in the isolation of remote communities in the Northern Territory (NT), a place that typically challenges the best teachers and the most dedicated teacher education students.

\section{The need for the 'Growing Our Own' program}

The literature supporting the need for the Growing Our Own program, especially in the NT, is compelling. What follows is a discussion of the statistical, research and media landscape that demonstrates, a) the need for vastly more Aboriginal teachers, b) the barriers to retaining teachers in remote community schools and c) the alternative approach used in Growing Our Own to overcoming these barriers. This foreground leads to an analysis of the Growing Our Own student recollections of their experiences, particularly in the ways they speak about time. 


\section{The need for more Aboriginal teachers}

Ten percent of Australian's live outside of urban areas (Ross, 2015). Yet, nationally, our education systems are struggling to provide a quality education to school students in rural and remote areas that make up this percentage. Education systems in the NT face many obstacles. Schools in remote areas are especially vulnerable.

Research evidence indicates that Aboriginal students have very high rates of absenteeism in the NT. For example, in 2014 only $37 \%$ of aboriginal students attended school more than $90 \%$ of the time (Dreise et al., 2016). Recent media reports (Aisthorpe, 2017) identified that more than half of students enrolled in NT schools were not attending school regularly. In fact, across remote areas of the NT, over 650 students had an attendance rate of just $31 \%$ in 2017 . Students need to attend school far more regularly in order to be 'successful' (Dreise et al., 2016; Lamb et al., 2015; Aisthorpe, 2017). One of the more disturbing statistical outcomes of reduced attendance for remote students is that they are only one third as likely as city students to meet international reading benchmarks (Ross, 2015). The issue of low attendance has therefore been, and continues to be, problematic, although the reasons for this are contested. While these statistics are distressing, it needs to be remembered that these types of statistics presume definitions of 'success' from a white, middle class perspective and set aside discussions of what actually determines 'success' from an Aboriginal perspective and whether these statistics even count in this debate.

Bringing more Aboriginal teachers into schools with Aboriginal students to address these needs is therefore logical (Price, 2016), especially in the NT where, for example, 44\% of the student population in Darwin is composed of Aboriginal students ${ }^{2}$. However, only $4 \%$ of highly qualified teachers in Darwin are Aboriginal. In remote schools, where there is a much higher percentage of Aboriginal students (often 100\%), there is an even lower percentage of Aboriginal teachers. The domination of the teaching profession by predominantly 'white' teachers, is also found in the United States (US). Research into the impact of teacher race on student achievement in the US showed that the lack of teacher diversity was detrimental to student achievement, while same culture/ethnicity teachers achieved better academic results for their students (Villegas and Irvine, 2010). The reasoning for this was purported to related to the higher teacher expectations of same culture teachers for their students (Villegas \& Irvine, 2010; Dee, 2004). Similarly, while white teachers in Australia were seen to have good intentions and took a strong social justice stance in teaching Aboriginal students, these good intentions were not enough to overcome the issues of achievement that Aboriginal teachers could (Luke, 2017). Aboriginal teachers showed distinct cultural differences in their approach to education (Malin, 1994). Social reformers now cite this 'Pygmalion Effect' or 'self-fulfilling prophecy' as the key to reversing prejudice in the classroom and encouraging child achievement, though this is difficult when prejudices and expectations are sometimes subconscious (Ellison, 2015; Luke, 2017). The implication for NT schools is that having Aboriginal teachers in classrooms will raise the expectations and therefore the 'success' of the students in their schools.

\section{Barriers to retaining teachers in remote community schools}

High rates of teacher attrition in remote schools also negatively impacts on student attendance and achievement. Quin (2016) argues that this is due to students not being able to build relationships with teachers primarily due to the lack of staff or constant change over of staff in these schools. Quin also identifies strong links between these issues and the very high attrition rates of the staff who are employed in rural and remote areas concluding that the situation in the NT is worse than anywhere else in Australia.

Media reports support this with around $70 \%$ of NT students attending schools in which principals had reported a lack of teaching staff with the next highest attrition rate reported for Tasmania, where $37 \%$ of schools lacked enough staff (Shipway, 2017). This is supported by research such as that by Downes and Roberts (2018) who argue that, despite decades of reviews and policy change, and the availability of more nuanced research, rural and remote schools remain hard to staff, and retention is difficult. It has also been found that around $16 \%$ of NT teachers leave their job each year; more than double that of any other Australian jurisdiction (Aisthorpe, 2016). The implication is that teachers appear to be reluctant to apply for NT teaching positions and, if they do take up NT positions, they don't stay long.

2 Source: NT Department of Education (2017) 
Related reports have found that NT teachers were more likely to suffer violence in the workplace (Shipway, 2017) and a third of teachers were on short-term contract, which could be further disincentive for them to work remotely (Shipway, 2017). NT teachers also encountered a higher cost of living, limited housing options, isolation, and a general feeling of culture shock (Ross, 2015). The inability of the NT education departments to both attract and keep its teachers is therefore understandable. Getting teachers to NT urban areas has become a massive challenge for the Government; enticing them to work in remote communities has been almost impossible. Government incentives have been tried, but have not been working (Ross, 2015). Quin (2016) rightly argues that these issues have had an extremely detrimental impact on both student engagement and attendance.

\section{Alternative approach used in Growing Our Own to overcome these barriers}

In response to all these difficulties and feedback from Aboriginal educators, a group of passionate Territorian educators from Charles Darwin University and the Catholic Education Office began to look at the problem from a different perspective. Instead of focusing on how to attract and retain quality teachers from distant metropolitan areas (who eventually or immediately left the remote area), why not focus on training Aboriginal people from within Aboriginal communities to be teachers?

A vision for Growing Our Own, grew from this group and, in 2008, they established a program that was to provide a generation of qualified Aboriginal teachers for remote Aboriginal schools while maintaining the integrity of Aboriginal communities in remote NT. The program was unique in that it delivered a Bachelor of Education (Primary) to Aboriginal Teaching Assistants in NT Catholic school, for the most part, in their home communities, where they concurrently worked as Aboriginal Teaching Assistants for three days a week, while attending university, in situ, on the other two days of the week. Student retention in the Growing Our Own program, and subsequent employment rates, have been impressive, with $74 \%$ retention and $90 \%$ employment. These percentages have been considerably higher than national standards across any other program offered for the past 10 years (CDU, 2017).

\section{Pedagogical approaches of Growing Our Own}

Growing Our Own has begun to build a pool of teachers that are already established in communities through a combination of three different pedagogical approaches in order to address these long-term issues in the NT. The pedagogies-work-integrated learning, place-based education, and a two-way (or both ways) teaching philosophy-overcame many of the issues of educational costs, and of students needing to leave family and community to gain a teaching degree. Given the levels of poverty and family/ cultural responsibilities in Aboriginal communities (especially remote ones), these are significant issues to be overcome.

Though not without their limitations, integrated learning and place-based models have proven to be an effective way to prepare indigenous people for the workplace across the world. In the NT, these integrated, place-based learning models are helping to 'bridge the gap' between westernised epistemologies and Aboriginal ways of knowing with the incorporation of a two-way or both-way mode of learning. Growing Our Own provides learning processes that are enhanced by existing Aboriginal Teaching Assistants being immersed in a learning community (the classroom), which gives them the ability to apply an academic, pre-service teacher training program in practice through an integrated teaching model (Dornan, Boshuizen, King, \& Scherpbier, 2007). Through respectful compromise, targeted approaches to teacher training, and examining research to avoid repeating past mistakes, Growing Our Own works to strengthen its effectiveness and reach. These three pedagogical approaches are briefly described here.

\section{Work-integrated learning}

Work-integrated learning is given to a program that integrates academic learning with immediate application in the workplace. No matter the context, students immediately acquire practical skills through exposure to the real world while receiving 'traditional' education. In the case of the integrated learning 
model used for Growing Our Own teacher education, participants work as Aboriginal Teaching Assistants and attend formal education classes. They are supported in this endeavor by both classroom mentors and a Growing Our Own mentor located in the school.

Work-integrated learning has numerous advantages both for the student's personal/work development and for their professional development. Stewart, Meadows, Bowman, van Vuuren \& Mulligan (2010) suggest that, while students tend to feel challenged by work-integrated learning and often have a heavier workload, they recorded positive outcomes. These outcomes included:

- significant shifts in their commitment, enthusiasm, and motivation;

- immediate feedback through workplace training and supported self-directed learning and collaboration;

- the mixture of workplace experience with 'traditional' classes helped the students to develop notetaking, critiquing, interview, and executive functioning skills.

Additionally, the role of the classroom mentor and the Growing Our Own mentor in work-integrated learning is vital. Westhuizen and Kesa (2014) found the most common advantages of being mentored was improved self-confidence and self-image, a sharper focus on career aspirations, the improved visibility of the mentee within the school/organisation, and the role modelling possible by the mentor for the mentee. All these benefits have been incorporated into the Growing Our Own program.

\section{Place-based approach}

Broadly, 'place-based education' has philosophical underpinnings dating back to John Dewey, Paulo Freire, Gregory Smith, David Sobel, and David Gruenewald (Deringer, 2017). It refers to targeting an entire community to address issues that exist within a specific location, generally at a community level, and is based on the belief that education and the experience of living cannot be separated. This ensures that the unique needs of every community are identified from a local perspective. The approach aims to help improve the health and well-being of those living in a specific area, enhancing the engagement of students and their overall performance.

Research has indicated that place-based education enhances the engagement of students and their overall performance (Smith, 2007, as cited in Molyneux \& Tyler, 2013). It was shown that students who were engaged in real-world learning were more likely to succeed than those who learnt the same material from textbooks (Powers, 2004, as cited in Molyneux \& Tyler, 2013). For example, a case study in India found that teaching must honour the lives of students and their pre-existing linguistic, cultural, and experiential knowledge, and teachers must view the local community and lifestyles as catalysts in learning, not as a deficit (Molyneux \& Tyler, 2013). The act of harnessing existing knowledge and resources empowered students and led to a transformed classroom. The key to this transformation was unpacking and celebrating the collection of an individual's knowledge, experiences, and questions, which are often marginalised, ignored, or dismissed (Molyneux \& Tyler, 2013).

However, one obstacle to place-based learning can be the reluctance of teachers to use the approach (Howley, Howley, Camper, \& Perko, 2011). This reaction epitomises the challenge of abandoning 'traditional' teaching methods for progressive instructional methods with a focus on place and the environment. At an institutional level, Growing Our Own lecturers often use a place-based approach in their units of work. Most lecturers have adapted their curriculum to incorporate community understandings and knowledges into their learning, and they continue to learn and adjust as they work in the Growing Our Own program to enhance the learning experience of the Growing Our Own students.

\section{'Two-ways' or 'both-ways' teaching philosophy}

'Two-ways' or 'both-ways' philosophy centres around a partnership between Aboriginal and non-Aboriginal people. It recognises that both groups can learn from the other. Relationships are built on compromise and respect and rely on education occupying a neutral space where neither side assume authority or 
dominance. Teaching, therefore, must occupy a neutral space between westernised ways of 'doing' education and Aboriginal cultures, where neither side takes up a position of superiority, dominance, or authority (Purdie, Milgate, \& Bell, 2011).

The contributions of two-ways/both-ways learning suggest that there is a professional determination to see effective and sustainable change towards equal education. Overwhelmingly, scholars agree that the answer to this does not lie in merely creating an education system that simply places Aboriginal content within an essentially western curriculum. For an educational system to be truly effective, Aboriginal people need to feel some healing from the wounds caused by colonisation, historical trauma, racism, and disparities in health, education and living conditions (Chino \& DeBruyn, 2006). Healing will not come from ongoing feelings of dominance and authority, but through compromise, negotiation, and respect. Australian research has shown that Aboriginal students struggle with westernised curriculum and testing. Furthermore, it was suggested that non-Aboriginal educators were detached and disengaged from Aboriginal social and cultural influences, and that this had greatly impacted on Aboriginal attendance, self-esteem, academic performance, and led to continued non-Aboriginal ignorance of Aboriginal ways of being (Purdie et al., 2011). In contrast, 'two-ways/both-ways' philosophy infers a partner relationship between Aboriginal and non-Aboriginal cultures. During the design stage, this approach was captured within the Growing Our Own program.

There is no doubt that language presents a difficult hurdle and cannot easily be remedied through compromise. With over 100 spoken languages within the NT, it is a major challenge to ask non- Englishspeaking teachers from Aboriginal communities to teach their lessons in English. However, it's important to remember that Australia is not the first country to face this challenge. When Papua New Guinea, for example, approached education by using a multiplicity of languages as a tool for improving teaching and learning, this helped the country move towards more equal education for all (Klaus, 2010). In the early 2000s, the country began a gradual introduction of the use of local indigenous languages in the early years of basic education, in contrast to their previous education system, which used English as the only medium of instruction (Klaus, 2010). Subsequent research has shown that students who attended schools using this approach became literate more quickly in their 'native' tongue, and learned English more quickly and easily than students of the past methods (Klaus, 2010). In addition, students were more excited, pro-active, self-confident, engaged, and inquisitive about learning as a result of this initiative (Klaus, 2010). A similar approach has been employed in the Philippines (Laureno, 2016) with education beginning in children's 'mother' tongue, and progressively moving to a full English curriculum over several years. Training people locally was paramount in this transition. Under the reform, local members of the community received basic training to be teachers within their home community. An obvious drawback to this approach was if untrained teachers lead instruction during kindergarten, Grade 1, and Grade 2; three very formative years in education (Klaus, 2010). However, Growing Our Own addresses this issue by providing a Bachelor of Education (Primary) for its Aboriginal students.

Theoretically, the combination of the three pedagogical approaches within the Growing Our Own program should be successful and have obvious benefits for both students and teachers. The obvious next question was therefore to ask the Growing Our Own students what they thought.

\section{Methodology}

In order to collect Growing Our Own student perceptions without lecturer influence, we accessed a very open research methodology, a collective biography. A collective biography, in the tradition of Haug et al. (1987) and more recently the work of Davies and Gannon (2006, 2011), allows for multiple recollections to become one 'voice' in relation to a set theme. This method allowed us to collect reflections from the Growing Our Own students and express the common thread found within these as one Growing Our Own student voice.

In choosing this method we were conscious that the Growing Our Own students ought not to feel influenced by their lecturers, and it was decided that we would bring in an 'outsider' to take the position of the 'etic' (outsider) researcher to combine with the experience of the lecturers giving an 'emic' (insider) perspective during data analysis (Pole \& Morrison, 2003). Our 'outsider' was external to the Growing 
Our Own program. The process involved a discussion with the Growing Our Own students about the research and data collection and emphasised that they did not have to participate in the research or could withdraw at any time.

The Growing Our Own students and our 'outsider' then designed the theme that they wanted to address about Growing Our Own. This was a risk, as we could have ended up with data that may not have related to anything we wanted to know, but it proved effective. The students were given the option of responding either individually or in groups to the questions they designed and the choice of journaling or recording their responses. We do not know how many individual participants provided data, as most responses were recorded and journaled in groups. We do know that four 'sets' of data were analysed. All written responses were received as typed text, as the Growing Our Own students typed their reflections directly onto their laptops and provided a copy to our 'outsider'. Verbal responses were transcribed into typed text later by our 'outsider'.

A Foucauldian discourse analysis was then applied to the textual data to explore the ways in which the students spoke about the Growing Our Own program, the lecturers, and the institutional and local community structures and demands. A Foucauldian discourse analysis focuses attention on the power relations that exist within the text (Humphry, 2014). In this case we were looking for the ideas, the structures and the influences that created ease or difficulty for the Growing Our Own students while they were studying in the Growing Our Own program. As part of this process, the 'sets' of data were collated, and various factors were identified as being embedded in the ways the Growing Our Own students described their experience of the Growing Our Own program. From the textual data, we identified factors that acted to liberate or constrain the students' efforts to engage freely in the BEd(Prim) program. These notions form the basis of the following analytical response. Three main ideas emerged from the data: success; the juggle of cross-cultural expectations; and time.

The following analysis is presented in two sections. Firstly, a brief summary of the ideas that came from the students' data is provided so that we can hear what they had to say about the Growing Our Own program in a pragmatic way. This material not only covers the positives of the program, but also includes critical and constructive feedback. Reflections of this nature were enabled by the openness we built into the research process and our willingness to accept this as a way to engage with the ongoing improvement of our practice. The students' openness came from students designing their own questions to which they responded. Their questions not only allowed discussion about what was working but also gave the opportunity to express strongly felt concerns that had arisen during their Growing Our Own experience.

\section{The Growing Our Own students speak}

The Growing Our Own students spoke strongly of factors supporting their ability to engage in Growing Our Own. In the next section, the notion of time will be expanded to explore more closely the issues of power embedded in the language used by the Growing Our Own students when they spoke about time. However, here we will look at the more pragmatic issues of relationships, flexibility, culture, success, and time raised by the students.

\section{... of relationships}

One of the big advantages of the Growing Our Own program was that the students had an intimate knowledge of the community, the families and the children with whom they were working. The program allowed them to tap into this knowledge by keeping them primarily in their community's school. This allowed them to build on their existing connections to the advantage of both their work and their study before transferring this knowledge to their final placement in a school outside their community. Growing Our Own gave them a way of being able to put what they learned into practice and the students saw the value of this approach.

Working in the community and with students that you have grown around gives you an advantage of being able to study in a context that you know and best suits you. 
They were proud of the connection they had been able to make through their study (the theory) and work (the practise) and wanted to share these changes as they began taking on more of a teacher identity.

The lecturers need to come and see how the Growing Our Own students work and visit their classrooms where they go and to see them how they have built up their confidence.

The students acknowledged that it was the Growing Our Own program that had allowed the connections to happen. However, they also explained that great flexibility is always needed if they are to do the juggling required in their lives. As discussed below, their family and cultural responsibilities would always come first.

\section{.... of sanctioned and embedded flexibility}

The students commonly spoke about Growing Our Own as being 'enabling' for them. Their talk of enablement was always connected to their talk of negotiating their lives, especially their negotiation of study, work, family and cultural responsibilities. Students appreciated the inbuilt flexibility of the Growing Our Own program that allowed them to effectively juggle their life circumstances.

What works best in the program is that you are able to study (part time) and work (fulltime) at the same time, which is a good incentive when you have a family you need to support.

The significance of family and cultural responsibilities was a constant presence in the way they spoke of the Growing Our Own program.

It is really hard leaving family behind because there is a lack of family support. E.g. a father looks after the kids whilst their mum is in Darwin and plays the role of being both parents mum and dad.

There is a time, we have to make a time, when it comes to sorry business and family meeting, community meeting, ceremonies, and all cultural awareness.

Like we have a kid, parents to look after, family's kids, you know sisters and brothers. Um, and when we have elderly person passed away, or there has been a passing in the community.

And we have sorry business, and some other responsibilities, responsibilities to the community, when we leave the classroom, and we leave the assignment in the middle.

The students expressed a feeling of pressure due to these multiple expectations. The problem did not seem to be that students had these responsibilities but that they needed the space to juggle the competing needs of culture/family and work/academia. Culture/family did not seem to have the space to accommodate this need and was therefore given priority as can be seen from the following statements:

Families might give us problems for missing out on things.

The lecturers need to know that when we are not there is it because we got responsibilities.

And those responsibilities that we are responsible for.

The students suggested that, to be supportive of them, Growing Our Own lecturers therefore needed to,

Understand that what we do in life, basically in our remote communities, a non-indigenous person would not understand where we, and how we, stand and how we live.

These responsibilities meant that some academic requirements, such as the two internal intensive study weeks held at the CDU campus each year became a challenge for some of the students. 
Although travel only covers about 1/10 of the school year, it is challenging to organise your family commitments when you are away. This includes picking up/dropping children off to school/day care and can create stress for the other partner who has to juggle their work commitments and family life for that given week. It also affects family income for that week if both parents are working due to the other taking off time to ensure family commitments are upheld. E.g. finishing of work early to pick up children.

These issues were often expressed in our visits to community and were a concern of our female students. While these women were not stopped from participating in the Growing Our Own program, they found varying levels of support from family/culture. In some circumstances, our students' community/family did not recognise that their women do this type of 'organisation' daily and then have to add study on top of their work and family obligations. 'Family' was not seen as men's responsibility and therefore, it became problematic for women when additional requirements were put in place by the academic culture. This is not meant as a judgement but an observation of what Growing Our Own students needed to negotiate.

Anecdotally, the Growing Our Own lecturers were very aware of the issues raised by the Growing Our Own students and worked alongside them in trying to help negotiate the culture/family and academic/work tensions. However, we (lecturers) also struggled with a lack of support from academic and bureaucratic structures that were not prepared to adjust to the flexibility required in the Growing Our Own program. In some cases, we were trying to act as a buffer between this and our students. For example, the government requirement for LANTITE testing (in English) of people operating in English as their third or fourth language, may preclude many of our students from graduation. One of the most valuable aspects of having the Growing Our Own students as teachers in classrooms is their bi/multilingualism, particularly in the community's mother tongue, a skill which renders many white teachers ineffective in overcoming the statistics presented earlier in this paper. Lobbying of government was one area being addressed to support Growing Our Own students. There is no requirement for any other CDU students to be competent in multiple languages, so this issue was unique to Growing Our Own.

\section{... of cultural knowledge and the way we learn}

The students had advice for the lecturers they worked with to understand the communities and culture they were engaging with:

We need more time. The lecturers need to know what we do in our own communities and school.

Some need to be informed of certain specific aspects of communities, as the context can be vastly different from community to community. This information is something that students of specific communities should be able to deliver, however they may need guidance if lecturers are looking for specific information.

But, in general, the Growing Our Own students supported the idea that most lecturers usually took the time to find out about each school's community context and work with it.

Yes, they do know about our school, our community and how it operates.

Growing Our Own students also had several very clear messages for lecturers and the program stakeholders (schools, university and Catholic Education Office (CEO), their mentors and mentor teachers and lecturers) that would help with their ability to do their work and study. Each of the following is simply good educational practice, easily done. Students suggested that Growing Our Own maintains a shared vision and clear communication.

Communication and liais[on] between schools, CDU and CEO could be improved.

The need for a clear purpose/direction that was shared between these stakeholders was emphasised by students. Students spoke about having to deal with conflicting information at various times. Again, 
the notion of competing demands was raised, this time between the three major institutions involved in Growing Our Own, as they tried to work together with students. Clarity between the three is therefore important so that confusion does not manifest within the program.

Growing Our Own students also wanted academics to talk less!

There is too much talking coming from the unit lecturers. We would like the lecturers to talk less and get us more engaged in their units.

Here is a very straightforward, simple, and slightly embarrassing request for academics to 'practise what they preach'. It is a timely reminder that as lecturers (many of us ex-school teachers), we need to actually engage in the practices and theories and philosophies we are teaching about.

\section{... of success}

Growing Our Own students thought that overall the program worked well and was a success.

I believe the program works. It has been proven to allow Indigenous students from remote areas to successfully finish their teaching degrees. It has allowed me to have a Growing Our Own level of academic support while studying and working full time. There are a lot of factors which also contribute to this success, but the program definitely works.

Students were proud of having their own Growing Our Own room to work in with the CDU lecturers and mentors. They could also access new information that was not available to them outside of the Growing Our Own program.

The program is currently working well at the moment, because we learn a lot of new knowledge that we have not heard or know of before. The program is also Growing Our Own because we get to do courses in our local community and our lecturers and Growing Our Own coordinators get to come over to work with us two days a week in the Growing Our Own classroom.

Finally, what they did see was of great benefit was that, regardless of whether they managed to finish the BEd(Primary) degree or not, they considered themselves privileged to have been involved in the Growing Our Own program.

The benefits I see from completing the program are becoming a teacher, stable income for my family, becoming a role model for my community and young Indigenous people. Even if I don't complete the program, gaining experience and knowledge from what you have learned helps to improve how effectively you are able to do your job. So, I could say that I have already benefited from the program without completing it yet.

\section{... of time}

Growing Our Own students talked about preferring to focus on one large task at a time rather than having multiple and competing activities. This was a distinct need being expressed by the Growing Our Own students about their university work. For this to happen, they wanted more time with the lecturers. The assumption here is that students would like more time with lecturers in community, rather than online.

We need more time and attention from the lecturers.

We need more time with lecturers, actually. You know, they come out to visit communities so we need more time with them to talk about our assignments, work, studies.

The purpose of this time seemed to be primarily assistance with assessment work. 
We also need catch up time on the assignment that we are doing. So, whatever assignment that has been delivered to us, we have to continue on that and the other assignment that comes in has to wait until we finish up the assignment.

When we come back we have to continue on with the same assignment instead of moving on to the new one. That is confusing us.

Students spoke of the pressure of the constant demands of a time-based, academic system. They needed the academic process to slow down and wait for them, so that they could focus on one task at a time rather than being confused between multiple tasks. They needed this to happen with the assistance of the lecturers. An important part of this assistance was lecturers making time for feedback when they were not physically present in community or when the students were at CDU for intensives.

[It] is challenging to get regular feedback from lecturers when you only have email and phone to rely on, as there is no time given to liaise with lectures after the intensives.

Time also impacted by the structure of the program.

Each community is allocated different times to study, this could be due to funding or the discretion of the host school that this is determined.

Time seemed to equate with success. The length of time related to the depth of success. For example, the 10 years that Growing Our Own had been established equated to a successful program.

The program works, the Growing Our Own Program, because it has started, well we are coming up to ten years now, so it would be in 2007, 2006 around there. So, this program here, this Growing Our Own, is working well with our four communities. Wadeye, Daly, Bathurst Island, and Katherine at St. Joseph College.

Similarly, lack of time was equated with a lack of success. While we recognise that, as with any teaching circumstances, some students found the work easy and others struggled, some could put in large efforts, others were limited. Therefore, there were contrasting responses such this quote compared the next quotes. Here the student is happy with the time given.

Um, the week has been set up for two days. It is good from my perspective. It is set from Tuesday to Wednesday.

However more of the students' comments were requesting additional hours be added to the days that lecturers visited.

But I would like to see in the future, would like to see that, um, can we finish up and go more than 2:30? Because when we do the two days in GOO we start at 8:30 - 2:30, which is not enough time. I reckon we should start at 8:30-4:00 and that would give us more time to finish off an assignment.

... we would need more extra times together from 8:30am to 3:15pm. This would give us more time to complete our Assessments and Assignments.

I believe that I am not given enough time (6hrs per week) to study a 4-year Batchelor degree. This puts more stress on a student over a long period of time and can be hard to maintain study focus for more than 4 years.

When asked themselves whether they get enough time on one assignment before being asked to work on another assignment, Growing Our Own students generally agreed that the lack of time between assignments was an issue and the multiple tasks being requested simultaneously was hard to juggle. 
No, because we only spend two-days in $\mathrm{GOO}$ and 3 days in the classroom and this makes it hard for us to complete one assignment [and move] to another.

It can be difficult to cover what is necessary for understanding, but this is more due to time constraints than the lecturer visiting.

The way in which the academic culture required Growing Our Own students to move through the course did not suit most students. Lecturers therefore acted as the bridge between academia and the Growing Our Own students, particularly for their assessment work. There was a suggestion that lecturers should make sure that Growing Our Own students had completed the current assignment before a new lecturer was sent to the community for a new unit/assignment.

It is. Because, um, when the lecturers come to visit our community to deliver the, any assignment which we all do, is when it comes to that assignment and the lecturer who is delivering the assignment to us, we need to stick with the lecturer and the assignment they are delivering to us to finish it off before changing it into another lecturer or another assignment.

\section{Time and power}

The analysis of this data suggests that, within the Growing Our Own program, time appeared to produce a form of power. Each of the four data 'sets' spoke of the notion of time to describe their participation within the Growing Our Own program. Time impacted on their lives, which impacted on their participation and thereby determine the success of their participation in the Growing Our Own program.

When students described time in a linear way (one event after another), they were also describing competing demands that required negotiation, created stress and produced difficult choices around their time as a student. Successful negotiation of these lineally described events generally required students to prioritise their actions and the order of importance of the events. This was viewed as a negative experience where hard choices had to be made. The Growing Our Own students saw only one way to succeed, and this meant putting one priority ahead of another and acting on each in turn. The only way they saw to overcome this pressure was to gain 'more time' which allowed them to engage with both priorities.

When students described events as synchronous (happening simultaneously), their talk of stress and competing choices and priorities was not present. In these descriptions, one event did not need to dominate another. Events where described as occurring without the negative impacts on the student. It was interesting to note that a) different students had different reactions to the same event. A description of an event could be linear for one group/person and synchronous for another; and b) talk could move from a linear discussion to a synchronous discussion if 'time' was altered. To describe this use of the language, specific examples from the data have been used, although these findings were reflected across all the data.

\section{Linear time}

The use of linear time in student talk was particularly prominent when the Growing Our Own students spoke of their ability to meet the competing demands of both a tertiary educational culture and the multiple aspects of their Aboriginal heritage. Where these two cultures (academic and Aboriginal) intersected and competed, time became a scarce resource and Growing Our Own students struggled to resolve the competing demands within that space.

The negotiation process required by students appeared to be accompanied by a lack of acknowledgement, by either culture, of the demands each was making on the Growing Our Own students. Students always chose to meet the demands of their Aboriginal culture, in which family and 'sorry' business were a priority, before meeting the demands of the academic culture. 
Growing Our Own students then also prioritise action in a linear way. Their first priority, for example their family, took precedence over their next priority, for example their assignment work. This is demonstrated in the following extract from the data.

There is a time, we have to make a time when it comes to sorry business and family meeting, community meeting, ceremonies, and all cultural awareness. Just what we need more time and attention from the lecturers. The lecturers need to know that when we are not there is it because we got responsibilities. And those responsibilities that we was responsible for. Like we have a kid, parents to look after, family's kids, you know sister's and brother's [children]. Um, and when we have elderly person passed away, or there has been a passing in the community. We need more time. The lecturers need to know what we do in our own communities and school.

Here, time for family and Aboriginal cultural activities was the chosen priority. The Growing Our Own students' response suggests that it was important that this be understood by the academic culture because Aboriginal culture had been prioritised over academic culture. The responsibility to Aboriginal culture was always greater than to academic culture. This means that time was devoted to Aboriginal culture first and then to academic work second. "The lecturers need to know that when we are not there it is because we got responsibilities."

In effect, this is a request to draw time from academic work in order to meet the time demands of family and cultural responsibilities: "Just what we need more time and attention from lecturers".

The events are also described one after the other. First, 'cultural responsibility' takes ownership of their time; second, lecturers and students exchange time. Again, in saying this, there is no judgement as to the choice (this is likely to be the same choice for many university students), just an observation of how this linear time allocation and prioritising was conducted.

And we have sorry business, and some other responsibilities, responsibilities to the community, when we leave the classroom, and we leave the assignment in the middle. When we come back, we have to continue on with the same assignment instead of moving on to the new one; that is confusing us.

Similarly, in this quote, Aboriginal culture is prioritised and there is a request to draw time from academic work. The language is assertively stating that academia should help students make up time that has been lost rather than forcing an arbitrary finishing date for their assigned work. The assignment will be put on hold while students looked after their other responsibilities and it is very important for lecturers to understand this point. When the Growing Our Own students return to the academic culture, lecturers and mentors need to be aware firstly, of the priority given to Aboriginal cultural responsibilities, and secondly, that time will need to be given for them to complete their assignment before starting on the next one.

The linear language drawn on by the students sounded almost desperate; 'we have to make time', 'we just need more time', 'lecturers need to know', 'we need more time', 'lecturers need to know what we do', 'we have responsibilities', 'we leave in the middle', 'we have to continue', '[it] is confusing'. The students use of these types of phrases indicates a point where the academic culture can act. It is at this point that alternatives can be put in place and students can be supported to negotiate around their study responsibilities. Negotiation of other support in communities might also be an option and could free up time for the academic requirements, but this may not be a high priority for Aboriginal students.

\section{Synchronous time}

When students described time in synchronous ways, they described events as happening simultaneously. When Growing Our Own students spoke of events synchronously, it appeared that they felt they had the power to achieve their goal of education. When time was spoken of in these ways, there seemed to be less pressure on students. The use of 'and' was prominent. Things fell together without the need to manipulate or prioritise time. 
It has allowed me to have a good level of academic support while studying and working full time.

What works best in the program is that you are able to study (part time) and work (fullime) at the same time. Which is a good incentive when you have a family you need to support.

The program is also good because we get to do courses in our local community and our lecturers and GOO coordinators get to come over to work with us two days a week in the Growing Our Own classroom.

These reflections from Growing Our Own students show that they are aware that negotiating between their responsibilities to family and community, and their commitment to academic study, is a large part of their learning through their participation in the Growing Our Own program. Their language is far from the stressed language of linear time in these quotes; 'allows me', 'support while xx and xx', 'you are able to xxx at the same time', 'good incentive when...', 'we get to ...', 'come over and work with us'. There is no sense of juggling or prioritising here, just confidently getting on with what needs to happen. It appears to indicate the level at which students are comfortable with the demands being made of them. It also strongly suggests that the overall organization of the Growing Our Own program is successful from their perspective.

\section{Applying Time}

The following, final quote shows where the overlap of linear and synchronous time occurs in the Growing our Own students talk and is also reflected in the quotes above.

The weeks intensives are more than enough time spent with lecturers to help with the unit being covered, however it is when students are sent back to the community and left to pick up where we left of, that the time catches up.

Here, synchronous time ('more than enough time') was consistently drawn on in relation to the overall organisation of the course. Linear time ('sent back', 'left to pick up where we left off' and 'time catches up') is consistently prominent in talk of the minutiae of unit and assessment work, and the negotiate of this with community and family responsibilities.

\section{Conclusion}

For students to gain the best from the Growing Our Own program, we went to them and asked them what they wanted to tell us about the program. They told us that they enjoyed being involved in the Growing Our Own program; they felt successful; and they were confident enough to want lecturers to share their pride in their development as teachers and to tell us to 'stop talking so much'. However, the students found it difficult to negotiate the competing demands of Aboriginal and academic cultures while undertaking their study. This competition was expressed through their use of linear and synchronous language about time.

Linear events seem to hold a dominating power over students and have the potential to be damaging, whereas synchronous events seem to free students to participate in the multiple areas of their lives comfortably. Reducing or altering linear events would allow for better and more fluid participation of students in the Growing Our Own program and, wherever possible, events should be structured so that students can speak of them as synchronous. We need to focus on ways to make this happen. The examples above suggest that the overall organisation of the 'Growing Our Own' program is not an issue. They also suggest that a look at the language being used can quickly identify if students are coping with what is being done within the program.

However, a focus on the management of time is suggested and should be carefully considered. We need to explore how certain events come to be synchronous (i.e. the overall organization of Growing Our 
Own) and others are seen as linear (the competing demands of assessment and unit work with family and culture) and focus on how to change 'linear' events to 'synchronous' events. While care needs to be taken for flexibility not to become an excuse for incomplete work, there are very strong reasons for time flexibility to be given consideration.

The overall message from our Growing Our Own students is that, like the perception of the Growing Our Own lecturers, Growing Our Own works for them. What we need to ensure is that this remains the predominant view and that we, as lecturers, continue to maintain open communication with our students and continue to listen to them to make ongoing improvements. 


\section{References}

Aisthorpe, J. (2016). NT teacher attrition rate worst in country. NT News. Retrieved from http://www. ntnews.com.au/news/northern-territory/nt-teacher-attrition-rate-worst-in-australia/news-story/8a6b0 9c60c40f1220cf720043cc49225

Aisthorpe, J. (2017). Students staying away from NT's classrooms. NT News. Retrieved from http://www. ntnews.com.au/news/northern-territory/stats-show-students-struggling-to-attend-school-in- nt/ news-story/a6dc9fddccf04241535f2a1fb56f14f6

CDU. (2017). Growing Our Own. Charles Darwin University. Retrieved Jan 2016 https://www.cdu.edu.au/ education/growingourown

Chino, M., \& DeBruyn, L. (2006). Building true capacity: Indigenous models for Indigenous communities. American Journal of Public Health, 96(4), 596-599. http://dx.doi.org/10.2105/ajph.2004.053801

Davies, B. \& Gannon, S. (2006). Doing collective biography: investigating the production of subjectivity. Berkshire, UK: Open University Press.

Davies, B. \& Gannon, S. (2011). Collective biography as pedagogical practice: being and becoming in relation to place. (pp 129-142). In M. Somerville, B. Davies, K. Power, S. Gannon and P. de Carteret (Eds.), Place Pedagogy Change. Rotterdam: Sense.

Dee, T.S. (2004). Teachers, race, and student achievement in a randomized experiment. Review of Economics and Statistics, 86(1), 195-210.

Deringer, S. A. (2017). Mindful place-based education: Mapping the literature. Journal of Experiential Education, 40(4), 333-348. doi:10.1177/1053825917716694

Dornan, T., Boshuizen, H., King, N., \& Scherpbier, A. (2007). Experience-based learning: a model linking the processes and outcomes of medical students' workplace learning. Medical Education, 41(1), 84-91. http://dx.doi.org/10.1111/j.1365-2929.2006.02652.x

Downes, N. \& Roberts, P. (2018). Revisiting the schoolhouse: A literature review on staffing rural, remote and isolated schools in Australia 2004-2016. Australian and International Journal of Rural Education, 28(1), 31-54.

Dreise, T., Milgate, G., Perrett, B., \& Meston, T. (2016). Policy Insights Issue \#4: Indigenous School Attendance: Creating expectations that are 'really high' and 'really real'. Camberwell, Vic: ACER.

Ebbeck, M. (2009). Evaluation of Growing Our Own - A two-way approach to teacher preparation for Northern Territory Catholic schools. Unpublished report: Charles Darwin University.

Ellison, K. (2015). Being honest about the Pygmalion effect. Discover Magazine. Retrieved from http:// discovermagazine.com/2015/dec/14-great-expectations

Giles, W. (2010). Teacher education in a remote community: Learning on the job. Asia-Pacific Journal of Cooperative Education, 11(3), 57-65.

Haug, F., Andersen, S., Bunz-Efferding, A., Hauser, K., Lang, U., Laudan, M., Ludemann, M., Meir, U., Nemitz, B., Niehoff, E., Prinz, R., Rathzel, N., Scheu, M., \& Thomas, C. (Eds.) (1987). Female sexualisation: a collective work of memory (E. Carter, trans). London: Verso Press.

Howley, A., Howley, M., Camper, C., \& Perko, H. (2011). Place-based education at island community School. The Journal of Environmental Education, 42(4), 216-236. http://dx.doi.org/10.1080/00958 964.2011 .556682

Humphry, N. (2014). Reconciling educationally displaced young people and education. Doctor of Philosophy thesis. School of Education, University of Wollongong. https://ro.uow.edu.au/ theses $/ 4022$ 
Klaus, D. (2010). The use of Indigenous languages in early basic education in Papua New Guinea: A model for Elsewhere? Language and Education, 17(2), 105-111. http://dx.doi. org/10.1080/09500780308666842

Lamb, S., Jackson, J., Walstab, A. \& Huo, S. (2015). Educational Opportunity in Australia 2015: Who succeeds and who misses out. Centre for International Research on Education Systems, Victoria University for the Mitchell Institute, Melbourne: Mitchell Institute.

Luke, A. (2017). Commentary: On the Race of teachers and Students: A Reflection on Experience, Scientific Evidence, and Silence. American Educational Research Journal, 54(1), 102S-110S.

Laureno, J. (2016). Philippines' Mother Tongue Based Multilingual Education Policy and Documentation: A Call for Inclusion of Special Education. Master of Education (International) Thesis. Charles Darwin University.

Malin, M. (1994). What is a good teacher? Anglo and aboriginal Australian views. Peabody Journal of Education, 69(2), 94-114.

Maher, M. (2010). Culturally responsive assessment and evaluation strategies for Indigenous teacher education students in remote communities of the Northern Territory of Australia. Australasian Evaluation Society Conference presentation, Wellington, New Zealand. Retrieved from https:// www.aes.asn.au/images/stories/files/conferences/2010/Papers/Maher,\%20Marguerite.pdf

Molyneux, P., \& Tyler, D. (2013). Place-based education and pre-service teachers: a case study from India. International Journal of Inclusive Education, 18(9), 877-887. http://dx.doi.org/10.1080/13603 116.2013.855265

Pole, C., \& Morrison, M. (2003). Ethnography for Education. Berkshire, England: Open University Press.

Price, K. (2016). More Aboriginal and Torres Strait Islander Teachers for Australian High-Needs Schools. In J. Lampert \& B. Burnett (eds.), Teacher Education for High Poverty Schools. Education, Equity, Economy, Volume 2. Cham: Springer.

Purdie, N., Milgate, G. \& Bell, H. R. (2011). Two-way teaching and learning: Toward culturally reflective and relevant education. Australian Council for Educational Research. Retrieved from https:// research.acer.edu.au/indigenous_education/38

Quin, D. (2016). Longitudinal and contextual associations between teacher-student relationships and student engagement. Review of Educational Research, 87(2), 345-387. http://dx.doi. org/10.3102/0034654316669434

Ross, M. (2015). How can we recruit more teachers to work in rural schools? The health sector could have the answer. The Conversation. Retrieved from https://theconversation.com/how-can-werecruit-more- teachers-to-work-in-rural-schools-the-health-sector-could-have-the-answer-50015

Shipway, G. (2017). Teacher shortage worry in Territory. NT News. Retrieved from http:// www.ntnews.com.au/news/northern-territory/nt-struggling-to-fill-teaching-positions-inpalmerston- tennant-creek-and-arnhem-land/news-story/84f0746ceb1572cc8d0a8b2d0d 9d2955

Stewart, H., Meadows, M., Bowman, L., van Vuuren, K., \& Mulligan, P. (2010). Indigenous Voice: a work- integrated learning case study in journalism education. Australian Journalism Review, 32(2), 59-72.

Villegas, A. \& Irvine, J. (2010). Diversifying the Teaching Force: An examination of Major Arugments. Urban Review. 42, 175-192.

Westhuizen, P., \& Kesa, H. (2014). Work integrated learning in Higher Education: partnerships: a continuing evolution. African Journal of Hospitality, 3(1), 1-14. 